\title{
Le candomblé au Brésil, ou l'Afrique réinventée
}

Au Brésil, durant l'époque coloniale, la société reposait sur une structure hiérarchique selon laquelle, lorsqu'un métis s'élevait socialement, il devenait automatiquement un «Blanc». Ce «blanchissement social», relaté par les voyageurs étrangers, devint une des caractéristiques fondamentales de la société brésilienne. L'importance des signes extérieurs d'appartenance à la culture blanche était considérable. Il fallait montrer que l'on maîtrisait les codes de la culture dominante pour pouvoir améliorer sa position sociale. Le brassage des cultures et le métissage racial étaient alors les bienvenus, mais toujours dans le sens du «blanchissement ».

Le candomblé, aujourd'hui synonyme de résistance culturelle des Noirs, est né à cette époque de l'interpénétration des cultures africaines, européennes et amérindiennes, qui a permis aux esclaves africains et à leurs descendants de préserver leurs traditions religieuses, tout en les adaptant aux nouvelles contingences. Religion fondée sur l'expérience directe de la transcendance, grâce à la possession divine qui entraîne la métamorphose de l'initié en orixá (divinité), le candomblé a considérablement modifié les différentes pratiques africaines. Celles-ci ont été rassemblées dans un même espace (le terreiro, ou maison-temple) et des éléments issus d'autres horizons culturels ont été incorporés.

Lorsque les esclaves débarquaient sur le sol américain, ils étaient rapidement baptisés. Leur instruction religieuse se réduisait à une présentation superficielle des principes religieux catholiques, qui soulignait surtout les qualités de soumission et de résignation de tout bon chrétien. La plupart des esclaves étaient destinés au travail dans les plantations et les moulins à sucre, où l'évangélisation se limitait à la messe dominicale.

Vers la fin du XVIII ${ }^{\mathrm{e}}$ siècle, avec le déclin de la culture de la canne à sucre dans les campagnes du Nordeste brésilien, l'Eglise catholique devint beaucoup plus présente dans la vie quotidienne des esclaves africains et des affranchis concentrés dans les villes. Ces derniers créèrent des confréries noires autour d'un saint ou d'une vierge, telle la confrérie de Notre-Dame du Rosaire, une vierge noire, celle de saint Benoît le Maure, l'un des saints préférés des esclaves africains, ou encore celle des Hommes Noirs, réunissant les Noirs affranchis.

Les esclaves se rassemblaient en «nations », terme qui renvoyait à une supposée origine ethnique commune. Pendant toute l'histoire coloniale, cette forme d'organisation avait été systématiquement encouragée par les autorités afin d'accentuer les différences entre les esclaves et de rendre plus difficile une rébellion comme celle qui éclata en Haïti en 1791. Chaque «nation» était aussi liée à une confrérie religieuse composée de Noirs revendiquant une même provenance africaine.

1 Chargée de recherche au CNRS, Laboratoire d'ethnologie et de sociologie comparative de Nanterre. Elle est l'auteur de La quête de l'Afrique. Pouvoir et tradition au Brésil (Karthala, 1999 ; édition brésilienne, 2004) et de Les Yoruba du Nouveau Monde. Religion, ethnicité et nationalisme noir (Karthala, 2005). 
Une des plus anciennes confréries, l'Ordre Tertiaire du Rosaire à Bahia, était formée exclusivement de Noirs angolais. Les Noirs jeje (Fon) se réunissaient dans la confrérie du Bon Jésus des Nécessiteux et les Nagôs (Yoruba) dans celle de Notre-Dame de la Bonne Mort. Ces confréries catholiques fonctionnaient comme de véritables sociétés d'entraide, donnant aux esclaves nécessiteux les moyens de racheter leur liberté.

Ces associations ont constitué la base de ce qui allait être les terreiros de candomblé, où l'on retrouve la même division en «nations »: des nations de culte ketu, ijexá, jeje, efon, nagô-vodum, angola, congo, sans compter le candomblé de caboclo où l'influence amérindienne est particulièrement présente. Aujourd'hui, ces «nations » de candomblé ont perdu leur connotation ethnique, elles ne renvoient plus à une réelle origine africaine, mais à des identités religieuses plus ou moins différenciées. Divisées entre cultes plus ou moins traditionnels, elles ont toutes été influencées par les pratiques religieuses africaines et catholiques.

C'est donc dans les villes que la religion des maîtres commença à se mêler à celle des esclaves, d'autant plus facilement qu'il existait des correspondances entre ces deux univers religieux. Cela donna naissance au syncrétisme afro-catholique : Jésus fut identifié avec Oxalá, le dieu de la création; Omolu, le dieu de la variole, fut assimilé à saint Sébastien, criblé de flèches, ou à saint Lazare, couvert de plaies ; Yansan, la déesse guerrière du vent et des tempêtes, fut associée à sainte Barbe.

Selon la tradition orale, le premier terreiro de candomblé fut fondé à Salvador de Bahia, dans la première moitié du $\mathrm{XIX}^{\mathrm{e}}$ siècle, par trois Africaines membres de la confrérie de Notre-Dame de la Bonne Mort. Jusqu'aux années 80, la dévotion catholique des pratiquants du candomblé demeura très forte. A la fin du processus d'initiation, le novice devait assister à une messe catholique et recevoir la bénédiction d'un curé. Encore aujourd'hui, les initiés du candomblé réalisent un rituel qui est devenu l'un des symboles de la culture bahianaise : le lavage des escaliers de l'église du Bonfim à Salvador. Le Christ du Bonfim (de la Bonne Mort) est en fait identifié à Oxalá, dont le principal rituel consiste à purifier les autels avec de l'eau sacrée.

\section{La lutte contre le syncrétisme afro-catholique}

De nos jours, le lien entre pratiques africaines et pratiques catholiques est remis en question par un mouvement dit de «désyncrétisation», qui vise à éliminer du candomblé toute influence catholique pour en laisser resurgir les racines africaines. Ce mouvement a vu le jour au début des années 80, lorsqu'un groupe de mães-desanto (prêtresses chefs d'un terreiro de candomblé) a signé un manifeste fustigeant le syncrétisme entre orixás africains et saints catholiques, héritage, selon elles, de l'époque coloniale où l'esclave était forcé de cacher ses dieux derrière les images des saints catholiques. Ces prêtresse reprenaient ainsi la «théorie du masque » de Bastide $^{2}$, qui interprétait le syncrétisme, chez les membres des maisons de culte «traditionnelles» de Bahia, comme une forme de résistance face à la culture dominante.

Aller à la messe après l'initiation, laver les escaliers d'une église, adresser les prières destinées aux orixás à des saints catholiques, étaient les signes d'une époque révolue. L'Afro-Brésilien devait prendre en main sa destinée et revendiquer son identité africaine, renouant avec ses racines. Or, ces comportements critiqués par un nombre restreint de leaders de candomblé étaient en réalité au fondement même de la

\footnotetext{
${ }^{2}$ R. Bastide, Les religions africaines au Brésil. Contribution à une sociologie des interpénétrations de civilisation, PUF, 1960 (rééd. 2001).
} 
tradition afro-brésilienne telle qu'elle était pratiquée, depuis toujours, à Salvador de Bahia.

Vingt ans plus tard, peu de choses ont changé dans les terreiros bahianais : le lien entre pratiques africaines et catholiques a été mis entre parenthèses, âprement critiqué par les défenseurs de la purification des traditions africaines, mais activement encouragé par l'office de tourisme local. Celui-ci aide, entre autres, à organiser la «traditionnelle» cérémonie du lavage de l'église du Bonfim ${ }^{3}$. Aujourd'hui la question est de savoir quelle tradition il faut retrouver : la tradition afro-brésilienne, produit du brassage de cultures africaines, européennes et amérindiennes, ou la « tradition africaine » ? Et dans ce dernier cas, de quelle tradition africaine s'agit-il ?

\section{La mise en valeur de la culture yoruba}

Dès le début des études afro-brésiliennes, une attention toute spéciale a été accordée à l'origine culturelle des différentes pratiques religieuses « africaines ». Il s'agissait en fait d'identifier les différentes composantes du peuple brésilien, afin de mesurer sa capacité à occuper une place importante sur la scène internationale. A la fin du XIX ${ }^{\mathrm{e}}$ siècle, les théories évolutionnistes défendaient l'existence d'une hiérarchie culturelle, morale et psychique entre les différents peuples. Ainsi, l'AngloSaxon était supérieur au Portugais, tel que le Yoruba par rapport aux autres Africains, et notamment aux Bantous, qui occupaient le dernier degré de l'échelle évolutive. Le débat sur la nécessité du métissage entraînait celui sur la dégénérescence inévitable du peuple brésilien, constitué de races considérées comme «inférieures ».

Le précurseur des études afro-brésiliennes, Raymundo Nina Rodrigues, s'attacha à démontrer la suprématie des Yoruba parmi les Noirs bahianais. Il réfutait ainsi la thèse communément admise à l'époque d'une prédominance culturelle bantoue, dont témoignaient pourtant les apports linguistiques et le folklore. Il chercha à prouver qu'il existait une «aristocratie » noire au sein des esclaves africains, formée par les Yoruba, ou Nagôs comme on les appelle au Brésil ${ }^{4}$. Il fut aidé en cela par l'arrivée tardive d'esclaves yoruba, à la suite de la chute de l'empire d'Oyo.

R. Nina Rodrigues et ses successeurs, Arthur Ramos et Edison Carneiro, inaugurèrent une alliance qui deviendra normative entre ethnologues et pratiquants de candomblé, attribuant un label traditionnel aux terreiros nagô et en particulier aux trois maisons de culte de Salvador, dans lesquelles ont été menées la presque totalité des recherches sur le candomblé : 1'Engenho Velho, le Gantois et l'Axé Opô Afonjá 5 .

A partir des années 30, la valorisation des Yoruba s'exprime par leur opposition aux Bantous, censés être inférieurs, dépourvus de traditions religieuses et pratiquant la sorcellerie. Les stéréotypes, maintes fois répétés dans les écrits des ethnologues, qui font des Yoruba un peuple supérieur et attaché à ses traditions, et des Bantous un peuple plus perméable aux influences externes, plus «syncrétique », deviennent avec

\footnotetext{
${ }^{3}$ Cette cérémonie est devenue tellement «traditionnelle » qu'elle a été exportée en France. Depuis la fin des années 90, un groupe de Brésiliens résidant à Paris organise, chaque juillet, le lavage du SacréCœur. Habillés en blanc, munis de vases remplis d'eau et armés de balais, ils lavent les escaliers de la célèbre église de Montmartre.

${ }^{4}$ R. Nina Rodrigues, Os Africanos no Brasil, São Paulo, Editora Nacional, 1932.

${ }^{5}$ S. Capone, La quête de l'Afrique dans le candomblé. Pouvoir et tradition au Brésil, Karthala, 1999 ; «Entre Yoruba et Bantou: l'influence des stéréotypes raciaux dans les études afro-américaines », Cahiers d'études africaines, 157, 2000.
} 
R. Bastide la preuve de la prédominance religieuse yoruba dans le candomblé traditionnel.

A partir des années 70, avec la redécouverte d'un orgueil racial - «Black is beautiful »-, le temps est venu de réaffirmer ses racines africaines. L'origine culturelle africaine qui sera mise en avant est alors la culture yoruba (nagô), magnifiée dans les écrits des ethnologues, dans les chansons et dans les romans bahianais. Le syncrétisme, qui avait été l'élément constitutif du mythe de la démocratie raciale, devient un fléau à combattre et le Yoruba devient le seul Noir résistant, qui a feint d'accepter la culture blanche pour mieux sauvegarder ses traditions africaines.

\section{Le mouvement de réafricanisation}

Si le syncrétisme n'est qu'un masque blanc posé sur des dieux noirs, il est donc possible de retrouver, dans un effort contre-acculturatif, la «pureté » des traditions africaines. Il suffit pour cela, si l'on en croit les mães-de-santo bahianaises à l'origine du mouvement contre le syncrétisme, d'étudier l'histoire de l'Afrique occidentale et la langue yoruba, et d'éliminer tout mélange avec le catholicisme. Or, ces prêtresses sont également très critiques à l'égard d'un autre mouvement qui prêche, lui aussi, le retour aux racines africaines : le mouvement de réafricanisation qui est né dans le sud du Brésil.

Las de dépendre des terreiros traditionnels de Salvador pour toute légitimation de leur statut religieux, certains pais-de-santo (prêtres) et mães-de-santo de São Paulo et de Rio de Janeiro ont commencé à renouer avec la terre des origines, en réalisant au Brésil des cérémonies sous la direction de prêtres yoruba ou en entreprenant des voyages vers l'Afrique, d'où ils reviennent chargés de titres honorifiques et de prestige $^{6}$. La recherche d'une tradition africaine "pure», opposée aux pratiques syncrétiques, permet alors à ces nouveaux «convertis », issus pour la plupart de l'umbanda, de déjouer les pièges de la soumission rituelle aux maisons de culte bahianaises. Celles-ci voient ainsi leur position d'hégémonie au sein du champ religieux afro-brésilien dangereusement menacée, d'où le souci constant de limiter l'influence du syncrétisme afro-catholique dans les terreiros de candomblé bahianais.

Ce mouvement de retour aux racines africaines a donné naissance à des conférences internationales rassemblant les initiés du candomblé ainsi que des adeptes d'autres cultes afro-américains ${ }^{7}$. Ces différents réunions ont pour but d'élaborer un patrimoine commun aux cultes afro-américains, réunis aujourd'hui sous l'appellation « religion des orixás » et caractérisés par des valeurs, une éthique et une esthétique partagées. La première de ces valeurs est la résistance : le système de croyance, à la base des différentes adaptations régionales de la religion des orixás, constituerait le fondement de tout mouvement de résistance culturelle au sein des communautés de descendants d'Africains en Amérique. Résistance politique et engagement communautaire seraient alors parmi les éléments fondateurs d'une éthique propre à la religion des orixás.

De nos jours, un certain nombre de chefs de culte de candomblé aspirent à un rôle de leader communautaire. Cet engagement politique, souvent en contact étroit avec les

\footnotetext{
${ }^{6} \mathrm{Au}$ sein des cultes afro-brésiliens réafricanisés, lorsque l'on parle d'Afrique, en tant que terre des origines, on fait toujours référence au pays yoruba, divisé entre le Bénin et le Nigeria.

${ }^{7}$ Les COMTOC (Conférences mondiales sur la tradition et culture des orixás) ont une fréquence biannuelle. La première a été organisée au Nigeria en 1981 et la neuvième a eu lieu, en août 2005, dans la ville de Rio de Janeiro.
} 
militants du mouvement noir, remet en question l'idée d'une transformation généralisée du candomblé en religion a-éthique, dont les objectifs principaux seraient l'enrichissement, le succès personnel et l'obtention du pouvoir. De même, ce lien clairement établi entre centres de culte et communautés noires contraste avec le processus d'universalisation du candomblé, qui est, depuis longtemps, une religion ouverte à tous, Blancs, Noirs et même descendants de Japonais ${ }^{8}$.

\section{La fin du mythe de la démocratie raciale}

Le mouvement de réafricanisation et la valorisation de la culture yoruba, en dépit de l'évidente multiplicité des contributions culturelles présentes dans le candomblé, semblent remettre en cause le mythe de la démocratie raciale, si longtemps prégnant dans la société brésilienne. L'élaboration de ce mythe a souvent été attribuée à Gilberto Freyre ${ }^{9}$, selon qui la douceur des rapports entre maîtres et esclaves aurait empêché une politique de ségrégation, telle qu'aux Etats-Unis. Cette image du Brésil, son savant mélange de « races » et de cultures, a aujourd'hui montré ces limites, grâce notamment à l'action du mouvement noir, qui ne cesse de dénoncer le racisme dissimulé dans la société brésilienne, exprimé par exemple par la trop faible représentation des Noirs à la télévision.

$\mathrm{Si}$, au sein des maisons de culte de candomblé, on trouve depuis longtemps des initiés de toutes les couleurs de peau, ceux-ci se reconnaissent tous en tant que héritiers d'une «culture africaine ». L'identité culturelle est en fait complètement indépendante d'une réelle appartenance «ethnique» ou «raciale»: c'est l'initiation religieuse qui permet d'acquérir cette nouvelle identité africaine - yoruba pour les plus traditionalistes. Le candomblé, religion typiquement brésilienne car constituée par les apports culturels africains, européens et amérindiens, se présente aujourd'hui comme une religion «africaine » qui aspire à une pureté qui n'a jamais existé. L'influence toujours plus forte du mouvement noir brésilien, qui est passé du discours intégrationniste des années 30 au discours séparatiste des années 70, pourrait déterminer dans le futur un changement dans la perception de cette religion, au moins au sein des maisons de culte les plus liées au mouvement de réafricanisation. C'est dans le candomblé que les militants noirs puisent leurs symboles, dans un imaginaire de résistance qui lie les Yoruba et leurs traditions religieuses aux communautés d'esclaves fugitifs, les quilombos.

En 1996 a été lancé le premier magazine consacré aux Noirs brésiliens, Raça Brasil, qui publie des articles dénonçant le racisme quotidien, mais aussi des rubriques de mode ou des reportages (Black) people. Titre de référence pour la classe moyenne noire, à ses débuts, il avait remplacé les signes zodiacaux par les orixás du candomblé : Exu, le dieu messager, à la place des Gémeaux, régis par Mercure, ou Yemanjá, la déesse de la mer, à la place des Poissons. On reprenait ainsi les caractéristiques de chaque orixá et les «stéréotypes de la personnalité mythique » décrits dans les ouvrages de Pierre Verger ${ }^{10}$, pour les associer à des comportements

\footnotetext{
${ }^{8}$ La ville de São Paulo accueille une grande communauté japonaise, au sein de laquelle on trouve aussi des prêtres et des prêtresses de candomblé.

${ }^{9}$ Le «mythe de la démocratie raciale » est en réalité une expression qui a été employée, pour la première fois, par Arthur Ramos dans les années 40. Cf. à ce sujet A. S. Guimarães, "Démocratie raciale », Cahiers du Brésil contemporain, 49-50, 2002, pp. 11-37 et G. Freyre, Maîtres et esclaves. La formation de la société brésilienne, Gallimard, 1952.

${ }^{10}$ P. Verger, Orisha, les dieux yorouba en Afrique et au Nouveau Monde, Métailié, 1982.
} 
humains. Les références à l'univers religieux afro-brésilien et le prestige découlant de leur utilisation sont de plus en plus présents au Brésil.

Cette quête de la «pureté » africaine s'accompagne aussi de la critique acérée du syncrétisme et de la réalité de la démocratie raciale. Le mouvement noir brésilien a longuement revendiqué un système de quotas pour les Afro-Brésiliens, inspiré par les politiques des Etats-Unis, et poursuit sa lutte contre la discrimination raciale, toujours niée par la fable de la rencontre harmonieuse entre les trois races, mythe fondateur de la nation brésilienne. La III $^{\mathrm{e}}$ Conférence mondiale des Nations Unies contre le racisme, la discrimination raciale, la xénophobie et l'intolérance, tenue en 2001 à Durban (Afrique du Sud), a marqué un changement radical des politiques brésiliennes sur la question raciale. Depuis le début de l'année 2002, le gouvernement brésilien a mis en place un système de quotas pour les «Afro-descendants » dans le service public et dans les universités fédérales. L'application de cette loi ne cesse de susciter un débat animé sur la validité d'une notion telle que « afro-descendant » dans un pays fortement métissé. L'idée d'un traitement préférentiel pour les descendants d'Africains met en avant une image du Brésil, métamorphosé en pays «multiethnique » qui ne serait plus formé de multiples mélanges, mais de groupes étanches au sein desquels seraient à l'œuvre des formes de fidélité ethnique. Cela remet directement en cause le processus de formation de la société brésilienne, dans lequel l'ethnicité n'a jamais été un élément déterminant.

Au Brésil, les Noirs ont longtemps accepté l'illusion que le métissage pouvait être la solution à la discrimination raciale, diluant la couleur par des mariages qui « amélioraient la race ». Au contraire de ce qui est défendu par les actuelles politiques ethniques, la « race » demeure étroitement liée à la position sociale : plus on grimpe dans l'échelle sociale, plus on devient «Blanc». Aujourd'hui c'est par la revendication d'une identité «africaine» que Noirs, Blancs, métis, initiés dans le candomblé, améliorent leur statut social et religieux, grâce au prestige découlant du processus de réafricanisation. Lorsqu'il s'agit des cultes afro-brésiliens, le paradis multiculturel brésilien semble ainsi déchiré entre la reconnaissance de la richesse et de la multiplicité de ses composantes, et la mise entre parenthèses de toute contribution qui remet en cause la «pureté » africaine. L'Afrique, mythique et rêvée, est devenue de nos jours la seule instance légitimatrice pour les Noirs comme pour les Blancs initiés dans le candomblé. Ultime paradoxe d'un pays métis qui rêvait de devenir blanc. 